\title{
High-Value, Cost-Conscious Care Attitudes in the Graduate Medical Education Learning Environment: Various Stakeholder Attitudes That Residents Misjudge
}

\author{
Serge B. R. Mordang, MSc ${ }^{\top}$ (D), Andrea N. Leep Hunderfund, MD, MHPE ${ }^{2}$, \\ Frank W. J. M. Smeenk, MD ${ }^{1,3}$, Laurents P. S. Stassen, $M D^{1,4}$, and Karen D. Könings, $P h D^{1}$ \\ 'Department of Educational Development and Research, School of Health Professions Education, Maastricht University, Maastricht, \\ The Netherlands; ${ }^{2}$ Department of Neurology, Mayo Clinic, Rochester, MN, USA; 'Department of Pulmonary Medicine, Catharina Hospital, \\ Eindhoven, The Netherlands; ${ }^{4}$ Department of Surgery, Maastricht University Medical Center, Maastricht, The Netherlands.
}

\begin{abstract}
BACKGROUND: Training residents in delivering high-value, cost-conscious care (HVCCC) is crucial for a sustainable healthcare. A supportive learning environment is key. Yet, stakeholders' attitudes toward HVCCC in residents' learning environment are unknown.

OBJECTIVE: We aimed to measure stakeholders' HVCCC attitudes in residents' learning environment, compare these with resident perceptions of their attitudes, and identify factors associated with attitudinal differences among each stakeholder group.
\end{abstract}

DESIGN: We conducted a cross-sectional survey across the Netherlands between June 2017 and December 2018. PARTICIPANTS: Participants were 312 residents, 305 faculty members, 53 administrators, and 1049 patients from 66 (non)academic hospitals.

MAIN MEASURES: Respondents completed the Maastricht HVCCC Attitude Questionnaire (MHAQ), containing three subscales: (1) high-value care, (2) cost incorporation, (3) perceived drawbacks. Additionally, resident respondents estimated the HVCCC attitudes of other stakeholders, and answered questions on job demands and resources. Univariate and multivariate analyses were used to analyze data.

KEY RESULTS: Attitudes differed on all subscales: faculty and administrators reported more positive HVCCC attitudes than residents ( $p \leq 0.05$ ), while the attitudes of patients were less positive $(p \leq 0.05)$. Residents underestimated faculty's $(p<0.001)$ and overestimated patients' HVCCC attitudes $(p<0.001)$. Increasing age was, among residents and faculty, associated with more positive attitudes toward HVCCC ( $p \leq 0.05$ ). Lower perceived health quality was associated with less positive attitudes among patients $(p<0.001)$. The more autonomy residents perceived, the more positive their HVCCC attitude $(p \leq 0.05)$. CONCLUSIONS: Attitudes toward HVCCC vary among stakeholders in the residency learning environment, and residents misjudge the attitudes of both faculty and patients. Faculty and administrators might improve their support to residents by more explicitly sharing their

Electronic supplementary material The online version of this article (https://doi.org/10.1007/s11606-020-06261-8) contains supplementary material, which is available to authorized users.

Received April 15, 2020

Accepted September 21, 2020

Published online November 2, 2020 thoughts and knowledge on HVCCC and granting residents autonomy in clinical practice.

KEY WORDS: attitudes; graduate medical education; high-value, costconscious care; learning environment; job characteristics.

J Gen Intern Med 36(3):691-8

DOI: $10.1007 / \mathrm{s} 11606-020-06261-8$

(c) The Author(s) 2020

\section{INTRODUCTION}

Rising healthcare costs, overuse of care, and wasted spending demand physicians who are trained to provide high-value, costconscious care (HVCCC). ${ }^{1-3}$ HVCCC requires weighing the benefits and harms of procedures and interventions, while also considering cost over time. Physicians are expected to estimate the value of care and provide cost-effective care. ${ }^{4}$ Practicing HVCCC can lead to better outcomes, reduced costs, and improved patient experience. ${ }^{5-7}$ Residency training is an opportune time to shape future physicians' behavior. ${ }^{8-10}$ A supportive learning environment is crucial, ${ }^{11,12}$ as workplace experiences form residents' future knowledge, attitudes, and behaviors. ${ }^{13-16}$

Learning environments are complex, dynamic phenomena that are shaped by various stakeholders. ${ }^{17}$ Faculty are residents' primary role models, ${ }^{18}$ provide residents with advice and feedback, ${ }^{19,} 20$ and are the main initiators of HVCCC discussions. ${ }^{21}$ Administrators play an important role in policy and financial issues. $^{22,}{ }^{23}$ Patients also form an integral part of residents' training and are increasingly involved in decision-making. ${ }^{24-26}$ Each stakeholder group brings a unique perspective to the issue of value and costs. For instance, patients often feel uncomfortable discussing costs of care, ${ }^{27}$ while administrators are under pressure to control costs. ${ }^{28}$ Understanding the attitudes of these important stakeholder groups toward HVCCC can thus provide valuable insights into the residency learning environment.

Attitudes feed into behavior in practice, ${ }^{29,30}$ as demonstrated by studies connecting specific physician attitudes with their usage of healthcare services. ${ }^{31-33}$ Stakeholders in the workplace exhibit their own attitudes and show their culture, beliefs, and behaviors through the hidden curriculum. ${ }^{34,} 35$ Social pressure arising from the hidden curriculum can have 
powerful effects on residents' attitudes and, possibly, their future behaviors. ${ }^{29,} 36,{ }^{37}$ Hence, if a resident sees how a key stakeholder propagates HVCCC, the resident's intend to perform HVCCC behaviors will be formed, either positively or negatively affecting the resident's attitude toward HVCCC. Understanding how residents perceive the HVCCC attitudes of influential stakeholders within the learning environment can thus provide insights into the hidden curriculum.

Specific individual beliefs and work contexts also shape attitudes toward HVCCC, habitual behaviors, and perceptions regarding benefits and drawbacks of HVCCC. ${ }^{38,39}$ Therefore, different variables, like demographics or training regions, ${ }^{15,} 40$ could bolster different beliefs regarding HVCCC and help clarify differences in HVCCC attitudes within stakeholder groups. Furthermore, residents' perceptions of job characteristics may affect their willingness to devote energy and apply their skills to their work. ${ }^{41}$ Job demands, aspects at work that call for physical or mental exertion, can invoke stress and exhaustion to perform a behavior, while job resources, aspects at work that are functional to accomplish work tasks, can induce motivation and productivity. ${ }^{42,43}$ Therefore, exploring the relation between residents' HVCCC attitudes and job demands and resources might help identifying which job characteristics are important to consider when promoting HVCCC behavior in the workplace.

Previous studies exploring the attitudes of physicians, administrators, patients, and learners toward HVCCC have typically focused on a single stakeholder group. ${ }^{39,44-47}$ In this study, we aimed to perform a more comprehensive examination of the residency learning environment. Consequently, we surveyed residents, faculty, administrators, and patients regarding their attitudes toward HVCCC. We also investigated residents' estimates of the HVCCC attitudes of other stakeholder groups and tested how the estimates differ from the embraced attitudes of these stakeholder groups. Furthermore, we examined what factors related to with attitudinal differences within each stakeholder group, and which job demands and resources related to residents' HVCCC attitudes.

\section{METHOD}

\section{Participants and Procedure}

We conducted a cross-sectional survey (distributed between June 2017 and December 2018) of residents, faculty, administrators, and patients across the Netherlands. The Ethical Review Board of the Netherlands Association for Medical Education approved this study (no. NERB814, amendment no. NERB817) before launch.

\section{Study Context: the Dutch Healthcare System Compared With the US Situation}

The Netherlands and the USA are among the ten highest healthcare expenditure per capita countries in the world. ${ }^{48}$ In the
Netherlands, $12.9 \%$ of the gross domestic product was spent on healthcare in 2018. In the USA, this percentage was 17.8. The Dutch healthcare system largely relies on public resources, whereas the American healthcare system depends mainly on the private sector. ${ }^{49}$ In the Netherlands, residents are trained in the workplace under supervision by faculty and have internships within several non(academic) hospitals, which is similar to residency education in the USA. Administrators in both contexts attend to the financial concerns of healthcare organizations. For the patient population in the Netherlands, there is a uniform approach where every patient has insurance and relatively low out-of-pocket costs. In the USA, nearly 1 in 12 persons are uninsured, ${ }^{50}$ health insurance is much more variable, and out-of-pocket costs can be substantial. ${ }^{51}$

\section{Survey Instrument}

Survey items included the Dutch version of the Maastricht HVCCC Attitude Questionnaire (MHAQ), which measures key dimensions of $\mathrm{HVCCC}^{4}$ on three subscales: (1) highvalue care, the degree to which the respondent thinks physicians should be responsible for the provision of high-value care; (2) cost incorporation, the degree to which the respondent thinks physicians should integrate costs in daily clinical practices; and (3) perceived drawbacks, which reflects the respondent's beliefs about potential negative consequences of HVCCC (see supplemental Appendix A for a description and example item for each subscale ${ }^{52}$ ). For the first two subscales, a higher score reflects a more positive attitude; for the third subscale, a lower score reflects a more positive attitude. Respondents indicated their extent of agreement using a fourpoint Likert scale ( $1=$ strongly disagree, $4=$ strongly agree $)$.

Demographic items for residents and faculty addressed age, gender, hospital name, training region, clinical experience (in years), training location, and specialty (surgical, non-surgical, and supportive, see Supplemental Appendix B). Items for administrators included age, gender, hospital name, training region, and type of administrator. Items for patients included age, gender, hospital name, medical specialty visited, number of inpatient admissions and/or outpatient visits (average per year), estimated number of physicians treating the patient, and self-perceived health (rated using a seven-point scale, from $1=$ very bad to $7=$ very good).

The resident version of the survey also included two items asking respondents to estimate the HVCCC attitudes of other stakeholders. Specifically, we asked residents to indicate the extent to which faculty, administrators, and patients would agree with a central item from subscale 2 and subscale 3 using the same four-point Likert scale. We decided not to ask an item from subscale 1 because general guidelines in medicine indicate physicians should provide high-value care to patients. ${ }^{53}$

Finally, residents answered the job demands-resources questionnaire, ${ }^{54}$ a 40 -item instrument that measures perceptions of five job demands, including work pressure, cognitive demands, emotional demands, role conflict, and hassles, and 
five job resources, including autonomy, social support, feedback, opportunities for development, and coaching (see supplemental Appendix $\mathrm{C}$ for a description and example item for each subscale). Residents responded to these items using one of two five-point Likert scales (either $1=$ never, $5=$ very often, or $1=$ strongly disagree, $5=$ strongly agree).

\section{Data Collection}

We approached hospital education committees from all academic training regions $(N=8)$, after which these committees recruited residents and faculty in several hospital meetings and formal educational events. We also recruited residents and faculty via a digital newsletter of the Dutch "Bewustzijnsproject," a project advocating HVCCC in postgraduate education. $^{2}$ Authors F.S. and L.S. recruited administrators from several hospitals. We approached patients via patient platforms (e.g., patient panel of a hospital), via a health insurance company in the Netherlands, and before and after consults in hospitals (after gaining approval from the hospital).

All residents, faculty, and administrators answered the questionnaire online; patients also had the option to answer on hardcopy. All respondents received an information letter and signed an informed consent.

\section{Data Analysis}

Descriptive summary statistics were reported as means with standard deviations or frequencies with percentages, as appropriate. We performed multiple imputations to deal with missing values. ${ }^{55}$ As participants were nested in hospitals, we used multilevel analyses to answer the research questions. We used multilevel ANOVA's to compare the means of different stakeholders' attitude scores on the subscales of the MHAQ. We assessed residents' estimations of other stakeholders' HVCCC attitudes and compared these with the actual HVCCC attitudes of these stakeholders, using multilevel independent $t$ tests for the aforementioned two items. We used multilevel regression analyses to examine the relations between HVCCC attitudes scores and the measured independent variables. We used a backward elimination procedure, as we had not set a sequence of adding variables a priori. ${ }^{56}$ For all analyses, we estimated the population mean $(\mu)$ and accompanying standard deviation (SD). We calculated the regression slope using $\beta$, determined statistical significance at $p<0.05$, and used confidence intervals (CI) when appropriate. Additionally, we calculated the effect size Hedges' $g(g)$ and considered an effect size above 0.8 as large. ${ }^{57}$ We conducted all analyses using IBM SPSS Statistics 25.0 for Windows (Armonk, NY: IBM Corp.).

\section{RESULTS}

A total of 312 residents, 305 faculty members, 53 administrators, and 1046 patients responded to the survey (Supplemental Appendix D lists several features of each group). In total, 3,348 (8\%) of 42,825 values were missing. Two hundred ninety-nine residents (96\%), 297 faculty members (97\%), and 53 administrators (100\%) filled out all items in the MHAQ. Patients collectively answered $88 \%(27,554 / 31,380)$ of all MHAQ items; the remaining $12 \%(3,826 / 31,380)$ were missing completely at random.

\section{HVCCC Attitudes of the Different Stakeholder Groups}

Figure 1 visualizes the mean scores per subscale and stakeholder group. Overall, faculty (abbreviated f) and administrators (abbreviated a) demonstrated more positive attitudes toward high-value care than patients (abbreviated $\mathrm{p})\left(\mu_{\mathrm{f}-\mathrm{p}}=0.08\right.$, $\left.p=0.002, g=4.19 ; \mu_{\mathrm{f}-\mathrm{p}}=0.11, p=0.03, g=5.97\right)($ Table 1$)$. They were also more likely to agree physicians should integrate costs in daily clinical practices compared with residents (abbreviated $\mathrm{r})\left(\mu_{\mathrm{f}-\mathrm{r}}=0.10, p=0.005, g=3.33 ; \mu_{\mathrm{a}-\mathrm{r}}=0.21, p\right.$ $=0.001, g=6.13)$ and patients $\left(\mu_{\mathrm{f}-\mathrm{p}}=0.15, p=<0.001, g=\right.$ $\left.6.54 ; \mu_{\mathrm{a}-\mathrm{p}}=0.27, p=<0.001, g=7.36\right)$. Residents endorsed more drawbacks to HVCCC than faculty $\left(\mu_{\mathrm{r}-\mathrm{f}}=0.13, p=<\right.$ $0.001, g=4.91)$ and administrators $\left(\mu_{\mathrm{r}-\mathrm{a}}=0.28, p=<0.001, g\right.$ $=8.20)$, but fewer drawbacks than patients $\left(\mu_{\mathrm{r}-\mathrm{p}}=-0.10, p=\right.$ $0.006, g=5.33$ ). Faculty, in turn, believed HVCCC had more potential drawbacks than administrators $\left(\mu_{\mathrm{f}-\mathrm{a}}=0.15, p=0.03\right.$, $g=4.29$ ), while both faculty and administrators believed HVCCC has fewer drawbacks than patients $\left(\mu_{\mathrm{f}-\mathrm{p}}=-0.23, p\right.$ $\left.=<0.001, g=12.07 ; \mu_{\mathrm{a}-\mathrm{p}}=-0.38, p=<0.001, g=18.16\right)$.

\section{Residents' Estimations of Other Stakeholders' HVCCC Attitudes}

Residents underestimated the attitudes of faculty regarding the physician's duty to incorporate costs in daily practice $(p=<$ $0.001, g=8.03)$ and overestimated faculty's attitude toward the drawbacks of HVCCC ( $p=<0.001, g=8.30)$ (Table 2). We found no significant differences between residents' estimations on administrators' attitudes and administrators' embraced attitudes. Residents underestimated patients' beliefs that HVCCC has drawbacks ( $p=<0.001, g=6.55$ ); patients identified more drawbacks than residents were aware of.

\section{Factors Associated With Attitudinal Differences Within Each Stakeholder Group}

Among residents, male gender and a non-surgical specialty were associated with more favorable attitudes toward highvalue care $(\beta=0.09,95 \% \mathrm{CI}=0.03,0.16, p=0.006 ; p=$ $0.006)$. However, male residents also endorsed more potential drawbacks $(\beta=0.13,95 \% \mathrm{CI}=0.04,0.21, p=0.004)$, as did younger residents $(\beta=0.02,95 \% \mathrm{CI}=0.03,0.00, p=0.01)$ and residents working in a surgical specialty compared with a supportive specialty $(p=0.03)$.

Among faculty, practicing in a supportive specialty was associated with more favorable attitudes toward high- 




Figure 1 Overview of the subscale scores of the MHAQ per stakeholder group.

value care compared with a surgical specialty $(p=0.002)$ and toward incorporation costs in daily practice compared with a surgical and non-surgical specialty $(p=0.02 ; p=$ 0.02 ). Older faculty members were more likely to believe physicians should incorporate costs $(\beta=0.01,95 \% \mathrm{CI}=$ $0.00,0.008, p=0.01)$ and less likely to endorse drawbacks of $\operatorname{HVCCC}(\beta=-0.01,95 \% \mathrm{CI}=-0.01,-0.00, p$ $=0.001)$. Hospital region was significantly associated with faculty's attitudes toward high-value care ( $p=$ 0.002 ) and cost incorporation $(p=0.004)$, but not with their beliefs about potential drawbacks. Among administrators, none of the variable measures predicted their attitudes toward HVCCC.
Among patients, more frequent hospital visits were associated with less favorable attitudes toward high-value care $(\beta=$ $-0.00,95 \% \mathrm{CI}=-0.01,-0.00, p=0.03)$ and cost incorporation $(\beta=-0.01,95 \% \mathrm{CI}=-0.01,-0.00, p=0.04)$. $\mathrm{A}$ higher number of physicians treating the patients was associated with more favorable attitudes toward cost incorporation ( $\beta=-0.03,95 \% \mathrm{CI}=-0.05,-0.00, p=0.03)$. More positive perceptions regarding their own health condition were associated with more favorable attitudes toward high-value care $(\beta=$ $0.03,95 \% \mathrm{CI}=0.01,0.06, p=<0.001)$ and cost incorporation $(\beta=0.06,95 \% \mathrm{CI}=0.03,0.08, p=<0.001)$, and less endorsement of drawbacks of HVCCC $(\beta=-0.07,95 \% \mathrm{CI}$ $=-0.10,-0.05, p=<0.001)$.

Table 1 Overview of the estimated population means $(\mu)$, standard error of the mean (SEM) and estimated population mean differences $(\Delta \mu)$ between stakeholders.

Estimated population mean differences

\begin{tabular}{|c|c|c|c|c|c|c|c|c|c|c|c|}
\hline & \multirow[t]{2}{*}{$\mu$} & \multirow[t]{2}{*}{ SEM } & \multicolumn{3}{|c|}{ Compared to residents } & \multicolumn{3}{|c|}{ Compared to staff physicians } & \multicolumn{3}{|c|}{ Compared to administrators } \\
\hline & & & $\Delta \mu$ & $p$ & $\mathbf{g}$ & $\Delta \mu$ & $p$ & g & $\Delta \mu$ & $p$ & g \\
\hline \multicolumn{12}{|l|}{ High-value care } \\
\hline \multicolumn{12}{|c|}{ Physicians should be responsible for the provision of high-value care } \\
\hline Residents & 3.14 & 0.024 & - & - & - & - & - & - & - & - & - \\
\hline Staff physicians & 3.19 & 0.025 & 0.049 & 0.084 & 2.04 & - & - & - & - & - & - \\
\hline Administrators & 3.23 & 0.052 & 0.087 & 0.105 & 3.03 & 0.038 & 0.471 & 1.31 & - & - & - \\
\hline Patients & 3.11 & 0.017 & -0.027 & 0.272 & 1.59 & -0.075 & $0.002 \dagger$ & 4.19 & -0.113 & $0.029^{*}$ & 5.97 \\
\hline \multicolumn{12}{|c|}{ Cost Incorporation } \\
\hline \multicolumn{12}{|c|}{ Physicians should incorporate costs in daily clinical practices } \\
\hline Residents & 2.69 & 0.027 & - & - & - & - & - & - & - & - & - \\
\hline Staff physicians & 2.78 & 0.027 & 0.097 & $0.005 \dagger$ & 3.33 & - & - & - & - & - & - \\
\hline Administrators & 2.90 & 0.062 & 0.210 & $0.001 \dagger$ & 6.13 & 0.113 & 0.082 & 3.49 & - & - & - \\
\hline Patients & 2.63 & 0.018 & -0.055 & 0.053 & 2.94 & -0.152 & $<0.001 \ddagger$ & 6.54 & -0.265 & $<0.001 \ddagger$ & 7.36 \\
\hline \multicolumn{12}{|c|}{ Perceived Drawbacks } \\
\hline \multicolumn{12}{|c|}{ Believe that HVCCC has potential negative consequences } \\
\hline Residents & 2.44 & 0.026 & - & - & - & - & - & - & - & - & - \\
\hline Staff physicians & 2.31 & 0.027 & -0.131 & $<0.001 \ddagger$ & 4.91 & - & - & - & - & - & - \\
\hline Administrators & 2.16 & 0.064 & -0.279 & $<0.001 \%$ & 8.20 & -0.148 & $0.033^{*}$ & 4.29 & - & - & - \\
\hline Patients & 2.54 & 0.016 & 0.102 & $0.001 \dagger$ & 5.33 & 0.233 & $<0.001 \$$ & 12.1 & 0.381 & $<0.001 \$$ & 18.2 \\
\hline
\end{tabular}

\begin{tabular}{|c|c|c|c|c|c|c|c|c|c|c|c|}
\hline & \multirow[t]{2}{*}{$\mu$} & \multirow[t]{2}{*}{ SEM } & \multicolumn{3}{|c|}{ Compared to residents } & \multicolumn{3}{|c|}{ Compared to staff physicians } & \multicolumn{3}{|c|}{ Compared to administrators } \\
\hline & & & $\Delta \mu$ & $p$ & $\mathbf{g}$ & $\Delta \mu$ & $p$ & g & $\Delta \mu$ & $p$ & g \\
\hline \multicolumn{12}{|l|}{ High-value care } \\
\hline \multicolumn{12}{|c|}{ Physicians should be responsible for the provision of high-value care } \\
\hline Residents & 3.14 & 0.024 & - & - & - & - & - & - & - & - & - \\
\hline Staff physicians & 3.19 & 0.025 & 0.049 & 0.084 & 2.04 & - & - & - & - & - & - \\
\hline Administrators & 3.23 & 0.052 & 0.087 & 0.105 & 3.03 & 0.038 & 0.471 & 1.31 & - & - & - \\
\hline Patients & 3.11 & 0.017 & -0.027 & 0.272 & 1.59 & -0.075 & $0.002 \dagger$ & 4.19 & -0.113 & $0.029^{*}$ & 5.97 \\
\hline \multicolumn{12}{|c|}{ Cost Incorporation } \\
\hline \multicolumn{12}{|c|}{ Physicians should incorporate costs in daily clinical practices } \\
\hline Residents & 2.69 & 0.027 & - & - & - & - & - & - & - & - & - \\
\hline Staff physicians & 2.78 & 0.027 & 0.097 & $0.005 \dagger$ & 3.33 & - & - & - & - & - & - \\
\hline Administrators & 2.90 & 0.062 & 0.210 & $0.001 \dagger$ & 6.13 & 0.113 & 0.082 & 3.49 & - & - & - \\
\hline Patients & 2.63 & 0.018 & -0.055 & 0.053 & 2.94 & -0.152 & $<0.001 \ddagger$ & 6.54 & -0.265 & $<0.001 \ddagger$ & 7.36 \\
\hline \multicolumn{12}{|c|}{ Perceived Drawbacks } \\
\hline \multicolumn{12}{|c|}{ Believe that HVCCC has potential negative consequences } \\
\hline Residents & 2.44 & 0.026 & - & - & - & - & - & - & - & - & - \\
\hline Staff physicians & 2.31 & 0.027 & -0.131 & $<0.001 \ddagger$ & 4.91 & - & - & - & - & - & - \\
\hline Administrators & 2.16 & 0.064 & -0.279 & $<0.001 \%$ & 8.20 & -0.148 & $0.033^{*}$ & 4.29 & - & - & - \\
\hline Patients & 2.54 & 0.016 & 0.102 & $0.001 \dagger$ & 5.33 & 0.233 & $<0.001 \$$ & 12.1 & 0.381 & $<0.001 \$$ & 18.2 \\
\hline
\end{tabular}

\begin{tabular}{|c|c|c|c|c|c|c|c|c|c|c|c|}
\hline & \multirow[t]{2}{*}{$\mu$} & \multirow[t]{2}{*}{ SEM } & \multicolumn{3}{|c|}{ Compared to residents } & \multicolumn{3}{|c|}{ Compared to staff physicians } & \multicolumn{3}{|c|}{ Compared to administrators } \\
\hline & & & $\Delta \mu$ & $p$ & $\mathbf{g}$ & $\Delta \mu$ & $p$ & g & $\Delta \mu$ & $p$ & g \\
\hline \multicolumn{12}{|l|}{ High-value care } \\
\hline \multicolumn{12}{|c|}{ Physicians should be responsible for the provision of high-value care } \\
\hline Residents & 3.14 & 0.024 & - & - & - & - & - & - & - & - & - \\
\hline Staff physicians & 3.19 & 0.025 & 0.049 & 0.084 & 2.04 & - & - & - & - & - & - \\
\hline Administrators & 3.23 & 0.052 & 0.087 & 0.105 & 3.03 & 0.038 & 0.471 & 1.31 & - & - & - \\
\hline Patients & 3.11 & 0.017 & -0.027 & 0.272 & 1.59 & -0.075 & $0.002 \dagger$ & 4.19 & -0.113 & $0.029^{*}$ & 5.97 \\
\hline \multicolumn{12}{|c|}{ Cost Incorporation } \\
\hline \multicolumn{12}{|c|}{ Physicians should incorporate costs in daily clinical practices } \\
\hline Residents & 2.69 & 0.027 & - & - & - & - & - & - & - & - & - \\
\hline Staff physicians & 2.78 & 0.027 & 0.097 & $0.005 \dagger$ & 3.33 & - & - & - & - & - & - \\
\hline Administrators & 2.90 & 0.062 & 0.210 & $0.001 \dagger$ & 6.13 & 0.113 & 0.082 & 3.49 & - & - & - \\
\hline Patients & 2.63 & 0.018 & -0.055 & 0.053 & 2.94 & -0.152 & $<0.001 \ddagger$ & 6.54 & -0.265 & $<0.001 \ddagger$ & 7.36 \\
\hline \multicolumn{12}{|c|}{ Perceived Drawbacks } \\
\hline \multicolumn{12}{|c|}{ Believe that HVCCC has potential negative consequences } \\
\hline Residents & 2.44 & 0.026 & - & - & - & - & - & - & - & - & - \\
\hline Staff physicians & 2.31 & 0.027 & -0.131 & $<0.001 \ddagger$ & 4.91 & - & - & - & - & - & - \\
\hline Administrators & 2.16 & 0.064 & -0.279 & $<0.001 \%$ & 8.20 & -0.148 & $0.033^{*}$ & 4.29 & - & - & - \\
\hline Patients & 2.54 & 0.016 & 0.102 & $0.001 \dagger$ & 5.33 & 0.233 & $<0.001 \$$ & 12.1 & 0.381 & $<0.001 \$$ & 18.2 \\
\hline
\end{tabular}

Compared to administrators

Note: $g=$ Hedges' $g$ effect size

$* p<0.05,+p<0.01, \neq p<0.001$ 
Table 2 Model comparisons for each subscale, testing whether the addition of 'stakeholder' as a variable significantly improved the model.

\begin{tabular}{|c|c|c|c|c|c|c|}
\hline \multirow[t]{2}{*}{ Model } & \multirow[t]{2}{*}{$N_{\text {par }}$} & \multirow[t]{2}{*}{-2 Log Likelihood } & \multicolumn{4}{|c|}{ Comparison between model 1 and model 2} \\
\hline & & & $\Delta X^{2}$ & $\Delta \mathrm{df}$ & F-ratio & $p$-value \\
\hline \multicolumn{7}{|l|}{ High-value Care } \\
\hline Model 1: Base model & 3 & 1141.720 & & & & \\
\hline Model 2: Base model + Stakeholder & 6 & 1129.292 & 12.59 & 3 & 4.167 & $.007 *$ \\
\hline \multicolumn{7}{|l|}{ Cost Incorporation } \\
\hline Model 1: Base model & 3 & 1886.556 & & & & \\
\hline Model 2: Base model + Stakeholder & 6 & 1847.278 & 39.28 & 3 & 13.367 & $<0.001 *$ \\
\hline \multicolumn{7}{|l|}{ Perceived Drawbacks } \\
\hline Model 1: Base model & 3 & 2271.622 & & & & \\
\hline Model 2: Base model + Stakeholder & 6 & 2189.496 & 82.13 & 3 & 28.825 & $<0.001 *$ \\
\hline
\end{tabular}

Note: $N_{\text {par }}=$ number of added degrees of freedom, each for every stakeholder. -2 Log Likelihood = statistical method used in multilevel analysis for estimating population parameters, displayed in smaller-is-better format $*=p<0.05$

\section{Relation of Job Demands and Job Resources with Residents' HVCCC Attitude}

The more autonomy residents reported, the more positive their attitudes toward high-value care $(\beta=0.05,95 \% \mathrm{CI}=0.01$, $0.10, p=0.03)$ and cost incorporation $(\beta=0.07,95 \% \mathrm{CI}=$ $0.02,0.11, p=0.008)$, and the fewer drawbacks they perceived $(\beta=-0.11,95 \% \mathrm{CI}=-0.16,-0.05, p=<0.001)$. Higher perceived work pressure also related to more positive attitudes toward high-value care $(\beta=0.05,95 \% \mathrm{CI}=0.02,0.09, p=$ $0.004)$ and cost incorporation $(\beta=0.09,95 \% \mathrm{CI}=0.04,0.15$, $p=<0.001)$. Opportunities for development positively related to high-value care $(\beta=0.07,95 \% \mathrm{CI}=0.02,0.12, p=0.01)$, while supervisory coaching negatively related to high-value care $(\beta=-0.06,95 \% \mathrm{CI}=-0.12,-0.01, p=0.02)$. Additionally, greater cognitive demands related to more favorable attitudes toward cost incorporation $(\beta=-0.09,95 \%$ $\mathrm{CI}=-0.16,-0.02, p=0.01)$, and the more emotional demands residents perceived, the more drawbacks they perceived $(\beta=0.08,95 \% \mathrm{CI}=0.02,0.14, p=0.01)$. See Supplemental Appendix E for a complete overview of measured independent variables for each stakeholder group.

\section{DISCUSSION}

This multisite survey study illuminates the attitudes of residents, faculty, administrators, and patients toward HVCCC. These groups represent key stakeholders in clinical learning environments where residents are expected to learn how to provide HVCCC.

Comparison of stakeholder attitudes toward HVCCC revealed several noteworthy differences, with faculty and administrators having the most positive attitudes toward HVCCC, and patients having the most negative. Faculty and administrators are challenged to steward healthcare resources in light of limited resources, ${ }^{58}$ act in accordance with societal developments (such as the Choosing Wisely campaign ${ }^{59}$ ), and adhere to evidenced-based medicine. ${ }^{60}$ Patients tend to focus predominantly on restoring their health ${ }^{61}$ and may lack information on how HVCCC can advance their health goals. Residents have to deal with this variation in attitudes. Their HVCCC attitudes are less favorable than faculty and administrators but more favorable than patients, which may reflect a natural developmental progression as residents transition from members of the lay public to members of the medical profession.

Because attitudes are internally held phenomena, residents must infer the attitudes of other stakeholders based on observations of their behavior, reports of others within the workplace, or impressions from the broader culture. We found residents underestimated the positive attitudes of faculty toward HVCCC but overestimated the positive attitudes of patients. These findings build on prior studies ${ }^{62}$ showing faculty's thoughts on HVCCC are not always evident to residents. Faculty may display wasteful role-modeling behaviors ${ }^{39}$ which contribute to a hidden curriculum that contradicts their positive attitudes toward HVCCC. Additionally, residents may be unaware of their patients' concerns or assume patients are better informed about the benefits of HVCCC than they actually are. Without this awareness, residents may fail to adequately address patient concerns, potentially compounding patients' skepticism toward HVCCC and excluding patients from active participation in healthcare decisions. ${ }^{63}$

Physicians working in supportive specialties have fewer patient-related tasks, ${ }^{64}$ which might explain why these physicians see fewer drawbacks of HVCCC. Ageing faculty and residents were more favorable toward cost incorporation, which may reflect accumulating clinical experience and increased confidence in decision-making. ${ }^{65}$ Faculty in different regions displayed different attitudes, confirming the impor-

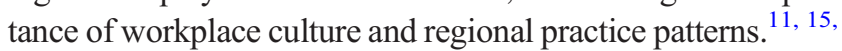
44 The same association was not present for residents, perhaps reflecting shorter exposure to these potential influences in the learning environment. For patients, lower rates of their own health made them less open to HVCCC. This is in keeping with prior studies showing patients are primarily concerned about their own health, ${ }^{61}$ viewing HVCCC as a construct that could detract from or harm their care.

Regarding job characteristics, autonomy positively related to residents' HVCCC attitudes. When residents feel they can make their own reasoned decisions, they might feel more confident and view $\mathrm{HVCCC}$ as an attainable challenge. Work pressure related 
to more favorable attitudes toward high-value care and cost incorporation. While high job demands can inhibit extracurricular activity, ${ }^{66}$ frontrunners of HVCCC may be overloading their tasks and thus experiencing more work pressure. Our findings indicate a relationship and not a causality, so work pressure may be a consequence of being more involved in HVCCC.

While stakeholders in the USA or other contexts may differ in their attitudes toward HVCCC, a similar pattern between stakeholders can be expected. Residents and faculty are similarly involved in patient care, administrators are responsible for managing finances, and patients are primarily focused on their health. In the USA, patients are generally receptive to discussing out-of-pocket costs, ${ }^{67,}{ }^{68}$ but remain very wary of incorporating societal costs into care decisions. ${ }^{67,} 69$ This distinction between out-of-pocket and societal costs ${ }^{70}$ will most likely matter more to patients in the USA, where average out-ofpocket costs are 1.97 times higher than in the Netherlands. ${ }^{71}$ Replication of this study in other contexts can help clarify how stakeholder attitudes toward HVCCC may differ as a result.

\section{Implications}

Our findings have several implications. First, it may be beneficial to forthrightly address the variation of HVCCC attitudes in the learning environment to help residents navigate the varying interests and perspectives they encounter. Senior faculty and specialty-specific teaching ${ }^{72}$ could play a role in this process. Second, the discrepancies between faculty's attitudes and residents' estimation of their attitudes suggest a need for faculty to more explicitly share their attitudes toward HVCCC and demonstrate these through their behavior, thereby setting good examples. Such role modeling is critical, as it represents a key mechanism by which social and occupational norms are transmitted. ${ }^{18,} 35,37$ Patients also set norms for residents in postgraduate education, ${ }^{73}$ but are misjudged by residents. Training residents effective and empathic strategies for eliciting patients' concerns and communicating the benefits of HVCCC may lead to more accurate perceptions and help boost patients' confidence in such care. Finally, more autonomy at the workplace might contribute to more favorable HVCCC attitudes and behaviors, although further studies are needed to better understand the direction of associations with autonomy and work pressure, and explore potential trade-offs (e.g., related to patient safety or resident well-being).

\section{Strengths and Limitations}

A strength of this study is that we surveyed multiple stakeholders from (non)academic hospitals geographically distributed over the Netherlands, supporting the study's generalizability. We pursued several options recruiting respondents to reduce selection bias, and the large number of respondents per stakeholder group supports the representativeness of each sample. However, our study also has limitations. Despite the large sample, we cannot assure that participants represent the entire population, because of bias in who decided to fill out the questionnaire. This bias is hard to prevent, but we hope our large sample warrants good quality of data. We saw an acceptable but considerable rate of missing responses with patients, due to patients indicating not knowing the answer. As missing values were at random across all items, it was unlikely that this affected our results. Additionally, we are unable to report a response rate given the nature of our sampling strategy. We also did not include all potential stakeholders in the clinical learning environment, e.g., nurses might also affect residents' thinking about HVCCC and could be involved in future research.

\section{CONCLUSION}

Residents, faculty, administrators, and patients exhibit different HVCCC attitudes in the clinical learning environment, and residents misjudge the attitudes of faculty and patients. Residents may benefit from educators forthrightly addressing this variation, encouraging faculty and administrators to explicitly share and model their positive views, and providing empathic patientcentered strategies for communicating benefits of HVCCC.

Corresponding Author: Serge B. R. Mordang, MSc; Department of Educational Development and Research, School of Health Professions Education, Maastricht University, Maastricht, The Netherlands (e-mail: s.mordang@maastrichtuniversity.nl).

Data Availability The Dutch dataset collected during the current study is available from the corresponding author on reasonable request.

\section{Compliance with Ethical Standards:}

The Ethical Review Board of the Netherlands Association for Medical Education approved this study (no. NERB814, amendment no. NERB817) before launch.

Conflict of Interest: Serge Mordang has nothing to disclose. Dr. Leep Hunderfund reports grants from American Medical Association, during the conduct of the study. Dr. Smeenk has nothing to disclose. Dr. Stassen has nothing to disclose. Dr. Konings has nothing to disclose.

Open Access This article is licensed under a Creative Commons Attribution 4.0 International License, which permits use, sharing, adaptation, distribution and reproduction in any medium or format, as long as you give appropriate credit to the original author(s) and the source, provide a link to the Creative Commons licence, and indicate if changes were made. The images or other third party material in this article are included in the article's Creative Commons licence, unless indicated otherwise in a credit line to the material. If material is not included in the article's Creative Commons licence and your intended use is not permitted by statutory regulation or exceeds the permitted use, you will need to obtain permission directly from the copyright holder. To view a copy of this licence, visit http://creativecommons. org/licenses/by/4.0/.

\section{REFERENCES}

1. Morgan DJ, Brownlee S, Leppin AL, Kressin N, Dhruva SS, Levin L, et al. Setting a research agenda for medical overuse. BMJ. 2015;351:h4534. https://doi.org/10.1136/bmj.h4534.

2. Specialisten CG. Bewustzijnsproject: Bewust kosteneffectief kwaliteit van zorg leveren in geneeskundig-specialistische vervolgopleidingen. 2015. 
3. American College of Physicians. Controlling health care costs while promoting the best possible health outcomes. Intern Med. 2009.

4. Owens DK, Qaseem A, Chou R, Shekelle P. High-Value, Cost-Conscious Health Care: Concepts for Clinicians to Evaluate the Benefits, Harms, and Costs of Medical Interventions. Ann Intern Med 2011;154:174-80.

5. Colla CH, Morden NE, Sequist TD, Schpero WL, Rosenthal MB Choosing wisely: prevalence and correlates of low-value health care services in the United States. J Gen Intern Med 2015;30(2):221-8. https://doi.org/10.1007/s11606-014-3070-Z

6. Chou R, Gaseem A, Owens DK, Shekelle P. Diagnostic imaging for low back pain: advice for high-value health care from the American College of Physicians Ann Intern Med. 2011;154(3):181-9.

7. Gaseem A, Alguire P, Dallas P, Feinberg LE, Fitzgerald FT, Horwitch C, et al. Appropriate use of screening and diagnostic tests to foster high value cost-conscious care. Ann Intern Med 2012;156:147-9.

8. Cooke M. Cost consciousness in patient care-What is medical education's responsibility? N Engl J Med 2010;362:1253-5.

9. King BC, Abramson E, DiPace J, Gerber L, Hammad H, Naifeh M. High value, cost-conscious care: Perspective of pediatric faculty and residents. Acad Pediatr 2016;16(6):e7. https://doi.org/10.1016/j.acap.2016.05 018

10. Weinberger SE. Educating trainees about appropriate and costconscious diagnostic testing. Acad Med 2011;86(11):1352. https://doi. org/10.1097/ACM.0b013e3182308db7

11. Stammen LA, Stalmeijer RE, Paternotte E, Oudkerk Pool A, Driessen EW, Scheele F, et al. Training physicians to provide high-value, costconscious care: A systematic review. JAMA. 2015;314(22):2384-400. https://doi.org/10.1001/jama.2015.16353

12. Weinberger SE. Providing high value cost-conscious care: A critical seventh general competency for physicians. Ann Intern Med. 2011 https://doi.org/10.7326/0003-4819-155-12-201112200-00019.

13. Asch DA, Nicholson S, Srinivas S, Herrin J, Epstein AJ. Evaluating Obstetrical Residency Programs Using Patient Outcomes. JAMA. 2009;302(12):1277-83.

14. Sirovich BE, Lipner RS, Johnston M, Holmboe ES. The association between residency training and internists' ability to practice conservatively. JAMA Intern Med 2014;174(10):1640-8. https://doi.org/10.1001/ jamainternmed.2014.3337

15. Chen C, Petterson S, Phillips R, Bazemore A, Mullan F. Spending patterns in region of residency training and subsequent expenditures for care provided by practicing physicians for medicare beneficiaries. JAMA. 2014;312(22):2385-93. https://doi.org/10.1001/jama.2014.15973

16. Dine CJ, Bellini LM, Diemer G, Ferris A, Rana A, Simoncini G, et al. Assessing Correlations of Physicians' Practice Intensity and Certainty During Residency Training. J Grad Med Educ 2015;7(4):603-9. https:// doi.org/10.4300/JGME-D-15-00092.1

17. Gruppen L, Irby DM, Durning SJ, Maggio LA. Interventions Designed to Improve the Learning Environment in the Health Professions: A Scoping Review. MedEdPublish. 2018;7(3). https://doi.org/10.15694/mep.2018. 0000211.1

18. Maudsley RF. Role models and the learning environment: Essential elements in effective medical education. Acad Med 2001;76:432-4

19. Passi V, Johnson S, Peile E, Wright S, Hafferty F, Johnson N. Doctor role modelling in medical education: Beme guide no. 27. Med Teach 2013;35(9):e1422-36. https://doi.org/10.3109/0142159X.2013. 806982 .

20. van de Wiel MW, Van den Bossche $\mathbf{P}$, Janssen $\mathbf{S}$, Jossberger $\mathbf{H}$ Exploring deliberate practice in medicine: how do physicians learn in the workplace? Adv Health Sci Educ Theory Pract 2011;16(1):81-95. https:// doi.org/10.1007/s10459-010-9246-3

21. Beck JB, McDaniel CE, Bradford MC, Brock D, Sy CD, Chen T, et al. Prospective Observational Study on High-Value Care Topics Discussed on Multidisciplinary Rounds. Hosp Pediatr 2018;8(3):119-26. https://doi org/10.1542/hpeds.2017-0183.

22. Molinaro C, Alexander J, Morlock L, Lyles AC. Does the hospital board need a doctor. Med Care 1995;33(2):170-85.

23. Weiner BJ, Shortell SM, Alexander J. Promoting Clinical Involvement in Hospital Quality Improvement Efforts: The Effects of Top Management, Board, and Physician Leadership. Health Serv Res 1997;32(4):491-510.

24. Chewning B, Bylund CL, Shah B, Arora NK, Gueguen JA, Makoul G. Patient preferences for shared decisions: A systematic review. Patient Educ Couns 2012;86(1):9-18. https://doi.org/10.1016/j.pec.2011.02. 004

25. Jarvis-Selinger S, Pratt DD, Regehr G. Competency is not enough: Integrating identity formation into the medical education discourse. Acad
Med 2012;87(9):1185-90. https://doi.org/10.1097/ACM. Ob013e3182604968

26. Batalden M, Batalden $\mathbf{P}$, Margolis $\mathbf{P}$, Seid M, Armstrong G, OpipariArrigan L, et al. Coproduction of healthcare service. BMJ Qual Saf 2016;25(7):509-17. https://doi.org/10.1136/bmjqs-2015-004315

27. Alexander GC, Casalino LP, Tseng CW, McFadde D, Meltzer DO Barriers to patient-physician communication about out-of-pocket costs. J Gen Intern Med 2004;19(8):856-60.

28. Begun JW, White KR, Mosser G. Interprofessional care teams: the role of the healthcare administrator. J Interprofessional Care 2011;25(2):11923. https://doi.org/10.3109/13561820.2010.504135

29. Armitage CJ, Conner M. Efficacy of the Theory of Planned Behaviour: A meta-analytic review. Br J Soc Psychol 2001:40:471-99.

30. Bohner G, Dickel N. Attitudes and attitude change. Annu Rev Psychol 2011;62:391-417. https://doi.org/10.1146/annurev.psych.121208. 131609

31. Cutler D, Skinner JS, Stern AD, Wennberg DE. Physician beliefs and patient preferences: A new look at regional variation in health care spending. Natl Bureau Econ Res. 2013.

32. Pearson SD, Goldman L, Orav EJ, Guadagnoli E, Garcia TB, Johnson PA, et al. Triage decisions for emergency department patients with chest pain: do physicians' risk attitudes make the difference? J Gen Intern Med 1995;10(10):557-64.

33. Tubbs EP, Broeckel Elrod JA, Flum DA. Risk Taking and Tolerance of Uncertainty: Implications for Surgeons. J Surg Res 2006;131:1-6.

34. Bandini J, Mitchell C, Epstein-Peterson ZD, Amobi A, Cahill J, Peteet J, et al. Student and Faculty Reflections of the Hidden Curriculum. Am J Hosp Palliat Care 2017;34(1):57-63. https://doi.org/10.1177/ 1049909115616359

35. Hill E, Bowman K, Stalmeijer R, Hart J. You've got to know the rules to play the game: how medical students negotiate the hidden curriculum of surgical careers. Med Educ 2014;48(9):884-94. https://doi.org/10.1111/ medu.12488

36. Hafferty FW. Beyond curriculum reform: Confronting medicine's hidden curriculum. Acad Med 1998;73:403-7.

37. Hafler JP, Ownby AR, Thompson BM, Fasser CE, Grigsby $\mathbf{K}$, Haidet $\mathbf{P}$, et al. Decoding the learning environment of medical education: a hidden curriculum perspective for faculty development. Acad Med. 2011;86(4):440-4. https://doi.org/10.1097/ACM.0b013e31820df8e2

38. Crano WD, Gardikiotis A. Attitude Formation and Change. Int Encycl Soc Behav Sci. 2015. p. 169-74.

39. Leep Hunderfund AN, Dyrbye LN, Starr SR, Mandrekar J, Naessens JM, Tilburt JC, et al. Role Modeling and Regional Health Care Intensity: U.S. Medical Student Attitudes Toward and Experiences With CostConscious Care. Acad Med 2017;92(5):694-702. https://doi.org/10. 1097/ACM.0000000000001223

40. Petterson S. The Imperative of Teaching Cost Consciousness in Graduate Medical Education. J Grad Med Educ 2015;7(4):681-2. https://doi org/10.4300/JGME-D-15-00404.1

41. Bakker AB, Demerouti E. The job demands-resources model: State of the art. J Manag Psychol. 2007;22(3):309-28. https://doi.org/10.1108/ 02683940710733115

42. Demerouti E, Bakker AB. The Job Demands-Resources model: Challenges for future research. SA J Ind Psychol. 2011;37(2). https://doi.org/ 10.4102/sajip.v37i2.974

43. Schaufeli WB, Bakker AB. Job demands, job resources, and their relationship with burnout and engagement: a multi-sample study. J Organ Behav 2004;25(3):293-315. https://doi.org/10.1002/job.248

44. Gupta R, Moriates C, Harrison JD, Valencia V, Ong M, Clarke R, et al. Development of a high-value care culture survey: a modified Delphi process and psychometric evaluation. BMJ Qual Saf 2016;0:1-9.

45. Ryskina KL, Smith CD, Weissman A, Post J, Dine JC, Bollman K, et al. U.S. Internal medicine residents' knowledge and practice of highvalue care: A national survey. Acad Med 2015;90(10):1373-9.

46. Goold SD, Hofer T, Zimmerman M, Hayward RA. Measuring physician attitudes toward cost, uncertainty, malpractice, and utilization review. J Gen Intern Med 1994;9:544-9

47. Colla CH, Kinsella EA, Morden NE, Meyers DJ, Rosenthal MB, Sequist TD. Physician Perceptions of Choosing Wisely and Drivers of Overuse. Am J Manag Care 2016;22(5):337-43.

48. Per capita health expenditure in selected countries in 2018 (in U.S. dollars). 2020. https://www.statista.com/statistics/236541/per-capitahealth-expenditure-by-country/.

49. Blank R, Burau V, Kuhlmann E. Comparative health policy: Macmillan International Higher Education. 2017. 
50. Health Insurance Coverage in the United States: 2018. 2019. https:// www.census.gov/library/publications/2019/demo/p60-267. html\#: : text $=$ The $\% 20$ percentage $\% 20$ of $\% 20$ people $\% 20$ with,in\%202017\%20(92.1\%20percent).

51. Hayes SL, Collins SR, Radley DC. How Much U.S. Households with Employer Insurance Spend on Premiums and Out-of-Pocket Costs: A State-by-State Look. 2019. https://www.commonwealthfund.org/publications/issue-briefs/2019/may/how-much-us-households-employer-insurance-spend-premiums-out-of-pocket. Accessed 25 May 2020

52. Mordang SBR, Konings KD, Leep Hunderfund AN, Paulus ATG, Smeenk F, Stassen LPS. A new instrument to measure high value, cost-conscious care attitudes among healthcare stakeholders: development of the MHAQ. BMC Health Serv Res 2020;20(1):156. https://doi. org/10.1186/s12913-020-4979-Z

53. American Medical Association. The code says: AMA Code of Medical Ethics' Opinion on Physician Stewardship. J Ethics 2015;17(11): 1044-5.

54. Bakker AB, Demerouti E. Job demands-resources theory. Wellbeing: A complete reference guide: Wiley. 2014. p. 1-28.

55. Schafer JL. Multiple imputation: a primer. Stat Methods Med Res 1999;8(1):3-15.

56. Myers RH, Myers RH. Classical and modern regression with applications. Belmont: Duxbury press; 1990.

57. Lakens D. Calculating and reporting effect sizes to facilitate cumulative science: a practical primer for t-tests and ANOVAs. Front Psychol 2013;4:863. https://doi.org/10.3389/fpsyg.2013.00863

58. Mitton C, Dionne F, Donaldson C. Managing Healthcare Budgets in Times of Austerity: The Role of Program Budgeting and Marginal Analysis. Appl Health Econ Health Policy 2014;12:95-102.

59. Bhatia RS, Levinson W, Shortt S, Pendrith C, Fric-Shamji E, Kallewaard M, et al. Measuring the effect of Choosing Wisely: an integrated framework to assess campaign impact on low-value care. BMJ Qual Saf 2015;24(8):523-31. https://doi.org/10.1136/bmjqs2015-004070

60. Straus SE, Glasziou P, Richardson WS, Haynes RB. Evidence-Based Medicine E-Book: How to Practice and Teach EBM: Elsevier Health Sciences. 2018.

61. Detsky AS. What Patients Really Want From Health Care. JAMA. 2011;306(22):2500-1.

62. Stammen LA, Slootweg I, Stalmeijer R, Janssen L, Stassen L, Scheele F, et al. The Struggle Is Real: How Residents Learn to Provide High-Value, Cost-Conscious Care. Teach Learn Med. 2019:1-10. https://doi.org/10. $1080 / 10401334.2019 .1583566$
63. Joseph-Williams N, Elwyn G, Edwards A. Knowledge is not power for patients: A systematic review and thematic synthesis of patient-reported barriers and facilitators to shared decision making. Patient Educ Couns 2014;94(3):291-309. https://doi.org/10.1016/j.pec.2013.10.031

64. Dijkstra IS, Pols J, Remmelts P, Bakker B, Mooij JJ, Borleffs JC, et al. What are we preparing them for? Development of an inventory of tasks for medical, surgical and supportive specialties. Med Teach 2013;35(4):e1068-77. https://doi.org/10.3109/0142159X.2012.733456

65. Morgan PJ, Cleave-Hogg D. Comparisons between medical students' experience, confidence and competence. Med Educ 2002;36:534-9.

66. Bakker AB, Demerouti E. Job demands-resources theory: Taking stock and looking forward. J Occup Health Psychol 2017;22(3):273-85. https://doi.org/10.1037/ocp0000056

67. Danis M, Sommers R, Logan J, Weidmer B, Chen S, Goold S, et al. Exploring public attitudes towards approaches to discussing costs in the clinical encounter. J Gen Intern Med 2014;29(1):223-9. https://doi.org/ $10.1007 /$ s11606-013-2543-9

68. Alexander GC, Casalino LP, Meltzer Do. Patient-Physician Communication About Out-of-Pocket Costs. JAMA. 2003;290:953-8.

69. Irwin B, Kimmick G, Altomare I, Marcom PK, Houck K, Zafar SY, et al. Patient experience and attitudes toward addressing the cost of breast cancer care. Oncologist. 2014;19(11):1135-40. https://doi.org/10. 1634/theoncologist.2014-0117

70. Peppercorn J. Financial Toxicity and Societal Costs of Cancer Care: Distinct Problems Require Distinct Solutions. Oncologist. 2017;22(2):123-5. https://doi.org/10.1634/theoncologist.2016-0301.

71. KFF analysis of data from IBM MarketScan Database. 2017. https:// www.healthsystemtracker.org/indicator/access-affordability/out-ofpocket-spending/.

72. Erath A, Mitchell M, Salwi S, Liu Y, Sherry A. The Sooner the Better: High Value Care Education in Medical School. Acad Med. 2019. https:// doi.org/10.1097/ACM.0000000000002881

73. Higashi RT, Tillack A, Steinman MA, Johnston CB, Harper GM. The 'worthy' patient: rethinking the 'hidden curriculum' in medical education. Anthropol Med 2013;20(1):13-23. https://doi.org/10.1080/13648470. 2012.747595

Publisher's Note Springer Nature remains neutral with regard to jurisdictional claims in published maps and institutional affiliations. 